\title{
The burden of travel on quality of life in stone patients
}

\author{
Kenneth T. Pace, MD, MSc, FRCSC \\ Division of Urology, St. Michael's Hospital, Unity Health Toronto and University of Toronto, Toronto, ON, Canada
}

Cite as: Can Urol Assoc J 2020; 14(4):105. hitp://dx.doi.org/10.5489/cuaj.6507

See related article on page 99

T

he negative impact of nephrolithiasis on patient quality of life (QOL) has been well-documented, ${ }^{1}$ but the impact that travelling to receive care and treatment of stones has not been well-studied. Narang et $\mathrm{al}^{2}$ performed a unique study, using a well-validated stone-specific patient-related outcome measures (PROM) instrument (the Wisconsin Stone Quality of Life questionnaire [WISQOL]) to investigate the impact of distance from treatment center on patient QOL. They showed that increasing distance is correlated with reduced WISQOL scores.

Due to the retrospective nature of the study and patientreported stone burden, it is impossible to tell if QOL scores were lower due to the actual distance travelled, or due to more severe stone disease. It is possible that patients with more complex stone disease or more complex medical comorbidities needed to travel further to receive treatment at a tertiary stone care center rather than at a local site (i.e., that their complex stone burden or comorbidities required travel to be managed appropriately). Of course, it is also possible that the need to travel a long distance, with possible attendant delays in care, financial burdens, accommodation challenges, and the like, could also contribute to reduced QOL.

These questions are particularly relevant in today's medical environment, with movement towards more regional- ized subspecialized care. They are also particularly relevant to Canadian urologists and patients; as the second largest nation in land area but with a low population density, it remains an ongoing challenge to provide urological care to remote and northern communities. Embracing technology to allow for virtual patient visits and assessments can help minimize the need for travel but not completely eliminate it - patients will still need to travel to receive interventional endourological care. It is important that urologists recognizing the burden and challenges such travel can have on patient QOL and financial security, but it is equally important for healthcare planners and administrators to ensure that adequate resources and patient supports are in place to minimize this burden when it cannot be avoided.

Competing interests: The author reports no competing personal or financial interests related to this work.

\section{References}

1. New F, Somani BK. A complete world literature review of quality of life (QOL) in patients with kidney stone disease (KSD). Curr Urol Rep 2016;17:1-6. http://dx.doi.org/10.1007/s11934-016-0647-6.

2. Narang $\mathrm{GL}$, Wiener LE, Penniston KL, et al. The effect of travel distance on health-related quality of life for patients with nephrolithiasis. Can Urol Assoc J 2020; 14:99-104. http://dx.doi.org/10.5489/cuai.6090

Correspondence: Dr. Kenneth T. Pace, Division of Urology, St. Michael's Hospital, Unity Health Toronto and University of Toronto, Toronto, 0N, Canada; kenneth.pace@utoronto.ca 